Urol. int. 1965;19:V

\title{
Inaugural Address
}

When we decided to organize a scientific meeting in Naples, we reviewed the possible subjects for such a meeting. The subject must fulfil the following conditions: it must be of general interest; it must be new but not so new that there was little to say; it must be of urological interest, without being solely urological. Endocrine surgery seemed to fulfil these requirements, and we chose three themes:

Endocrine surgery in prostatic carcinoma

Parathyroidectomy in renal lithiasis

Endocrine surgery in intersexuality which should be the subjects of three symposia we now began to prepare.

In a period of intense specialization in medicine, there are certain clinical and pathological aspects which appear to form a sort of "no man's land”, neglected by everybody. Their study poses numerous very special problems which must be approached by many specialists at the same time.

This was the purpose of our organizing the International Meeting on Endocrine Surgery. $\mathrm{W}$. We hoped that out of this joint study might come not universallyvalid conclusions-that would be asking too much-but a betterunderstanding of certain points a broadening of horizons so thatthis meeting could serve not as an end but as a starting point forfuture encounters and investigations. M. Sorrentino 